\title{
Synthesis of Gamma-Alumina from Kankara Kaolin as Potential Zeolite Active Matrix
}

\author{
*S.G. Bawa, A.S. Ahmed and P.C. Okonkwo \\ Department of Chemical Engineering, Ahmadu Bello University, Zaria, 810261, Nigeria \\ [Corresponding author, Email: sgbawa@gmail.com]
}

\section{ABSTRACT}

Commercial fluid catalytic cracking catalysts are manufactured using zeolites dispersed on an amorphous matrix, which is mostly alumina. Alumina is widely used as catalyst support in many heterogeneous catalytic processes owing to its high surface area, superior chemical activity and low cost. In compounded zeolite catalyst it serves as the active matrix which aids the conversion of the bulkiest molecules in the feed owing to its larger pore size than zeolite. Large specific surface area gamma-alumina $\left(\mathrm{Y}-\mathrm{Al}_{2} \mathrm{O}_{3}\right)$ was synthesized by hydrothermal method using Kankara kaolin as starting material. Thermal treatment of ammonium alum prepared from the filtrate of the dealuminated metakaolin was employed to obtain the alumina. Crystalline aluminum sulfate with $39 \mathrm{wt} \% \mathrm{Al}_{2} \mathrm{O}_{3}$ was obtained at calcination temperature of $800{ }^{\circ} \mathrm{C}$ with $3 \mathrm{~h}$ soaking. Gamma-alumina was produced at $850^{\circ} \mathrm{C}$ with $3 \mathrm{~h}$ soaking time, having specific surface area of $166 \mathrm{~m}^{2} / \mathrm{g}$. The weight percent of $\mathrm{Al}_{2} \mathrm{O}_{3}$ content in the synthesized and commercial gamma-alumina were $85 \%$ and $89 \%$ respectively as obtained from the XRF analysis. Good comparison was also observed in the diffractogram of the synthesized and commercial gamma-alumina from the XRD analysis. The Scanning Electron Microscopy (SEM) image showed the platy hexagonal shape of the gamma-alumina.

Keywords: Gamma-alumina, zeolite, kaolin

\section{INTRODUCTION}

The current fluid catalytic cracking (FCC) catalysts consist of a complicated combination of different materials, which have different functions (Corma, 1992). The pore size of the zeolite limits the activity to the molecules that access the active sites. Commercial FCC catalysts are manufactured using 1-2 $\mu \mathrm{m}$ zeolite dispersed on an amorphous matrix forming $60 \mu \mathrm{m}$ particles (Scherzer, 1993). Zeolites are microporous aluminosilicate minerals used for numerous commercial and domestic applications. The content of zeolite in zeolite catalyst is not greater than 3-15\% (Salahudeen et al., 2014). Zeolite Y is used commercially as catalyst in petroleum refinery because of its high concentration of active acid sites, its high thermal stability, high size selectivity and its crystal size is in the approximate range of $0.2-0.5 \mu \mathrm{m}$ and pore diameter of $7.4 \AA$ (Htay, 2008). The matrix comprises $60-80 \%$ commercial FCC catalyst and usually contains synthetic and natural components (Wang, 2006; Htay, 2008). Clay is the natural component and amorphous silica or silica-alumina is the synthetic portion (Htay, 2008). Matrix composition can influence catalyst performance but to a lesser extent than the zeolite component (Scherzer, 1994). An active matrix contains acid sites associated with aluminum atom, e.g. alumina (Hosseini, 2011). The active matrix is characterized by high surface area and they usually enhance bottom conversion and gasoline octane number (Scherzer, 1993). Among the different alumina available, gamma-alumina is the most important one that is used in catalyst formulation (Scherzer, 1993; Wang, 2006; Hosseini, 2011), due to its high surface area, thermal stability, outstanding mechanical properties and nature of interaction with zeolite active phases (Salahudeen, 2012). Alumina heated at temperature below $1100^{\circ} \mathrm{C}$ is considered as amorphous materials in spite of the fact that they have important adsorptive and catalytic properties (Santos, 2000; Hosseini, 2011). Above $1100^{\circ} \mathrm{C}$ it changes into crystalline alpha-alumina phase (Santos, 2000). The most 
common method of producing alumina is by the hydrothermal technique and the reaction takes place in water medium. Solvothermal process involves the use of organic solvent (Santos, 2000). The absence of commercial deposits of bauxite, being the primary source of alumina, in Nigeria, as well as the rapid depletion of bauxite deposits globally call for urgent development of alternative sources of alumina production (Aderemi, 2009). The production of alumina from Kankara kaolin in Katsina State, Nigeria has been reported in literature (Aderemi, 2009) but the target applications were not as catalyst support. On the other hand most of the works on the development of alumina support have been from conventional raw materials; bauxite and corundum (Kloprogge, 2002; Meor-Yusoff, 2007). This study was aimed at the preparation of high surface gamma-alumina from Kankara kaolin, with large pore size and to compare it with the commercially available gamma-alumina.

\section{MATERIALS and METHODS}

White grade raw kaolin was sourced from Kankara town in Katsina State, Nigeria, by selective mining and wet beneficiation process carried out in accordance with reported procedures (Ahmed, 1987; Edomwonyi-Otu, 2009). The beneficiated kaolin was calcined to $750^{\circ} \mathrm{C}$ for $2 \mathrm{~h}$, to obtain the reactive phase of kaolin known as metakaolin. For batch, $50 \mathrm{~g}$ of metakaolin was mixed in $185 \mathrm{ml}$ distilled water and properly stirred. $169 \mathrm{ml} 96 \mathrm{wt} . \%$ sulfuric acid was added to the mixture in a fume cupboard. After about $30 \mathrm{~min} 286 \mathrm{ml}$ water was added to quench the reaction. The product was filtered using high vacuum pump (ES-100, Edward, England) filtration set-up using sinta glass as filtering medium. Thirty-three (33) $\mathrm{g}$ of ammonium sulfate (Analar grade BDH, Poole, U.K) was completely dissolved in the filtrate and cooled in a refrigerator (Thermocool, C1202, England, U.K.) at $0^{\circ} \mathrm{C}$ for $6 \mathrm{~h}$. The ammonium alum crystals formed were filtered using the filtration set-up, then dried at $250^{\circ} \mathrm{C}$ for $4 \mathrm{~h}$ in an electric oven (TM OV-420, $0-260^{\circ} \mathrm{C}$, Gallenkamp, England, U.K.). The dried alum was calcined at various temperatures ranging from $700^{\circ} \mathrm{C}$ to 900 ${ }^{\circ} \mathrm{C}$, and the soaking time was varied from 1 to $4 \mathrm{~h}$ in an exposed element furnace (TIKIR 11/12, Heraeus, Holland). The elemental composition (in oxide form) of the products obtained were determined using the Energy Dispersive X-Ray Florescence (ED-XRF) machine (Mini Pal 4, PANalytical, Holland), and the X-ray diffraction (XRD) patterns were obtained using diffractometer (Empyreal, PANalytical, Holland) employing $\mathrm{Cu}$ Ka radiation $(\lambda=0.154 \mathrm{~nm})$. The textural properties (surface area, pore size and pore volume), of the products were determined from Brunauer-Emmett-Teller (BET) technique by $\mathrm{N}_{2}$ adsorption at $-196^{\circ} \mathrm{C}$ using Tristar 3000 Micrometrics equipment. The morphology was determined using Emission Scanning Electron Microscope (Zciss) at 20000 magnification.

\section{RESULTS and DISCUSSION}

Figure 1, shows the trend of specific surface area of ammonium alum calcined at $800^{\circ} \mathrm{C}$ for different soaking time. Decrease in surface area was observed between soaking time of $1 \mathrm{~h}$ and 2 $h$, while increase in pore size was equally observed in Figure 2, the observations were attributed to the coalescing of the nuclide of the product which resulted in loss of surface area and increase in pore size. From $2 \mathrm{~h}$ of soaking time to $3 \mathrm{~h}$, an increase in surface area and decrease in pore size were observed which could be as a result of rearrangement of the atoms of the material and hence the formation particles with smaller pores, which resulted in higher surface area. From $3 \mathrm{~h}$ to $4 \mathrm{~h}$ of soaking time, about $10 \%$ decrease in specific surface area was observed. The pore volumes of the calcination products obtained were in the range of 0.22 $\mathrm{cm}^{3} / \mathrm{g}$ to $0.41 \mathrm{~cm}^{3} / \mathrm{g}$ (Figure 2). 


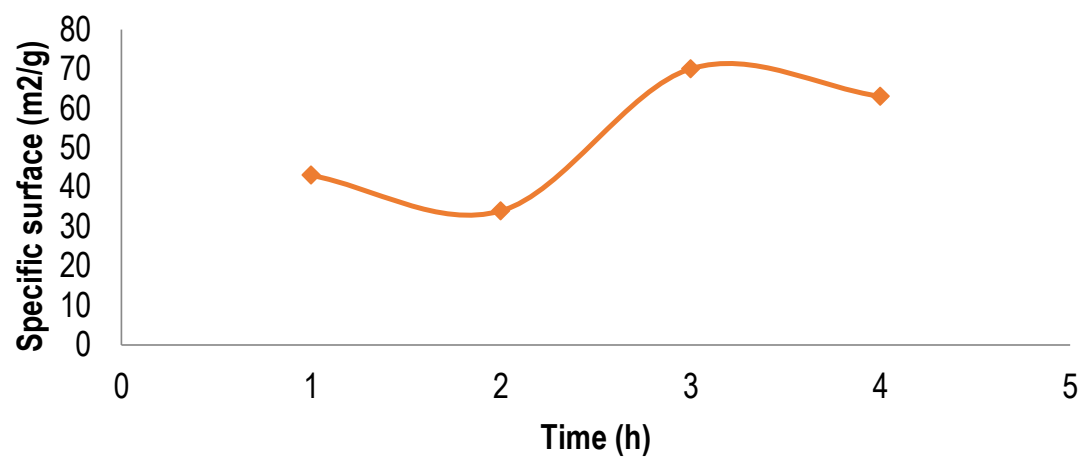

Figure 1: Specific Surface Area with Variation in Soaking Time at $800^{\circ} \mathrm{C}$

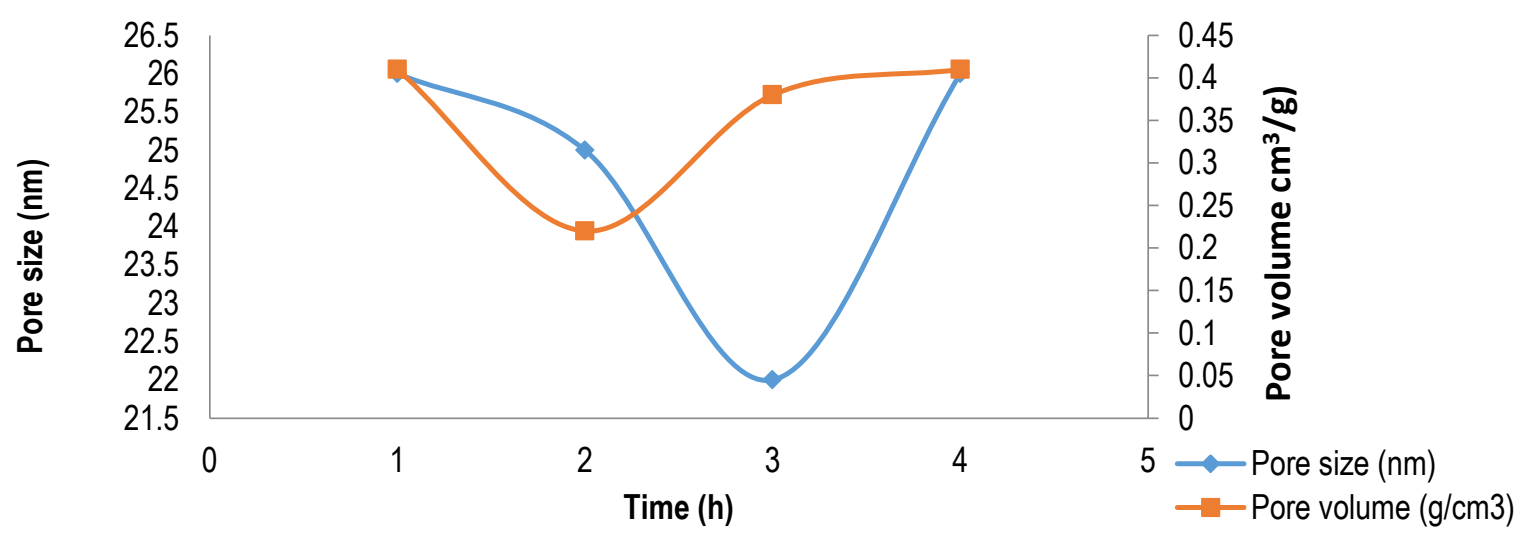

Figure 2: Pore Size and Pore Volume with Variation in Soaking Time at $800^{\circ} \mathrm{C}$

Specific surface area was observed to generally increase from $20 \mathrm{~m}^{2} / \mathrm{g}$ to $155 \mathrm{~m}^{2} / \mathrm{g}$ as temperature increased from $700^{\circ} \mathrm{C}$ to $900{ }^{\circ} \mathrm{C}$ as shown in Figure 3. A rapid increase in specific surface area was observed between $800{ }^{\circ} \mathrm{C}$ and $850^{\circ} \mathrm{C}$ (i.e. from $70 \mathrm{~m}^{2} / \mathrm{g}$ to $166 \mathrm{~m}^{2} / \mathrm{g}$ ) which accounted for $137 \%$ increase in specific surface area. This value gave an indication of the development of a new material with high surface area which was confirmed by the XRD patterns to be gamma-alumina.

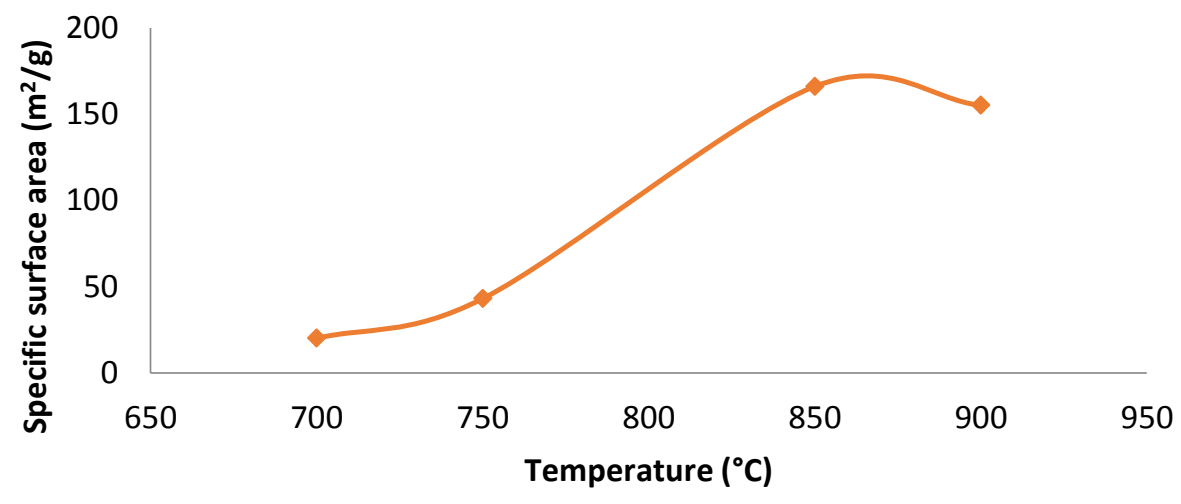

Figure 3: Specific Surface Area with Variation in Calcinations Temperature for $3 \mathrm{~h}$ 


\section{Nigerian Journal of Basic and Applied Science (December, 2016), 24(2): 66-72}

Heat treatment at $850^{\circ} \mathrm{C}$ and $900^{\circ} \mathrm{C}$ produced gamma-alumina with large specific surface area values of $166 \mathrm{~m}^{2} / \mathrm{g}$ and $155 \mathrm{~m}^{2} / \mathrm{g}$ respectively. It has been reported that porous materials having a surface area value above $100 \mathrm{~m}^{2} / \mathrm{g}$ is considered having a high surface area and is a potential material for catalyst support (Wefers, 1987). Calcination temperature of $850^{\circ} \mathrm{C}$ for $3 \mathrm{~h}$ gave the highest specific surface area (Figure 3). The products obtained had relatively large pore sizes ranging from $20 \mathrm{~nm}$ to $30 \mathrm{~nm}$ as shown in Figure 4. Resistance to mass flow in and out of the pores will be negligible when in use, owing to relatively smaller pore size of zeolite being about $0.74 \mathrm{~nm}$ (Figure 4). The pore size of the gammaalumina was found to be about 27 times that of zeolite Y, which agrees with Čejka (2010). Figure 4 shows that large pore volume was observed at calcination temperature of $850^{\circ} \mathrm{C}$ and $900^{\circ} \mathrm{C}$.

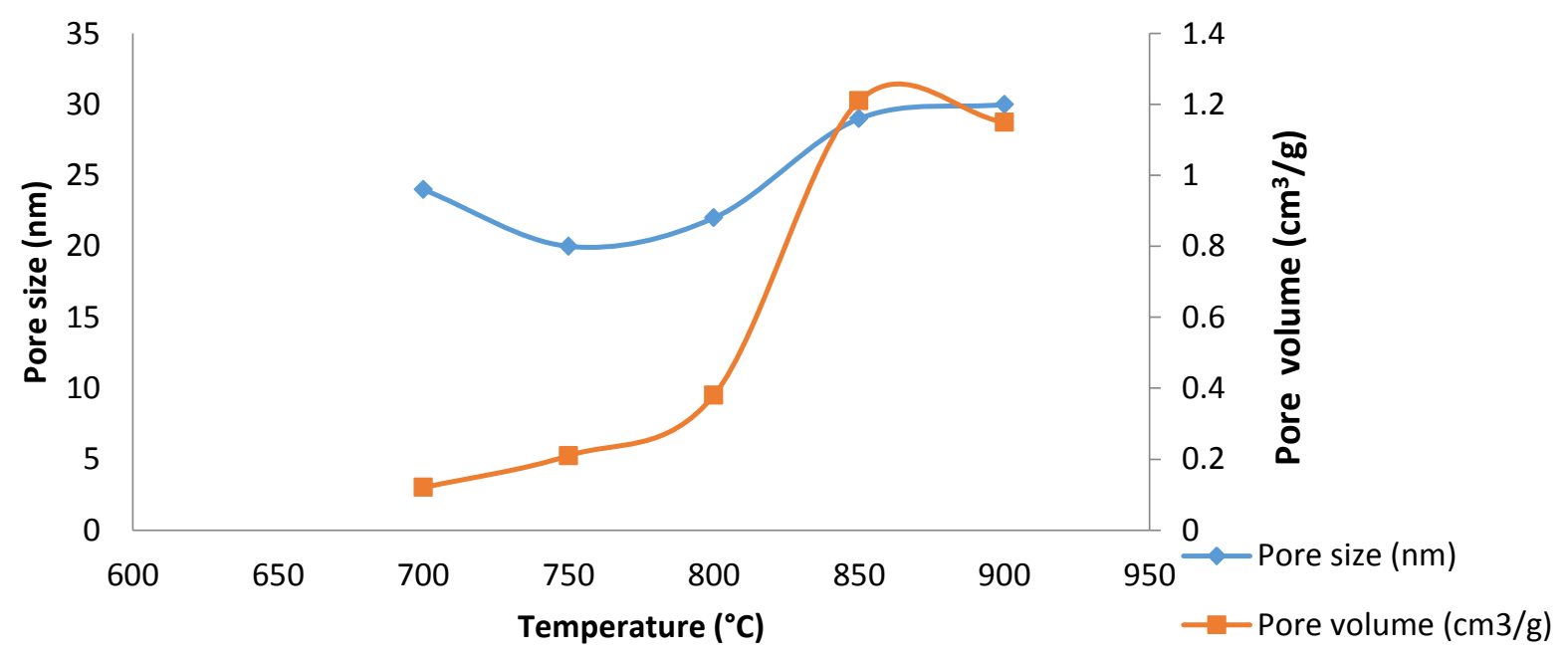

Figure 4: Pore size and Pore Volume with Variation in Temperature for $3 \mathrm{~h}$

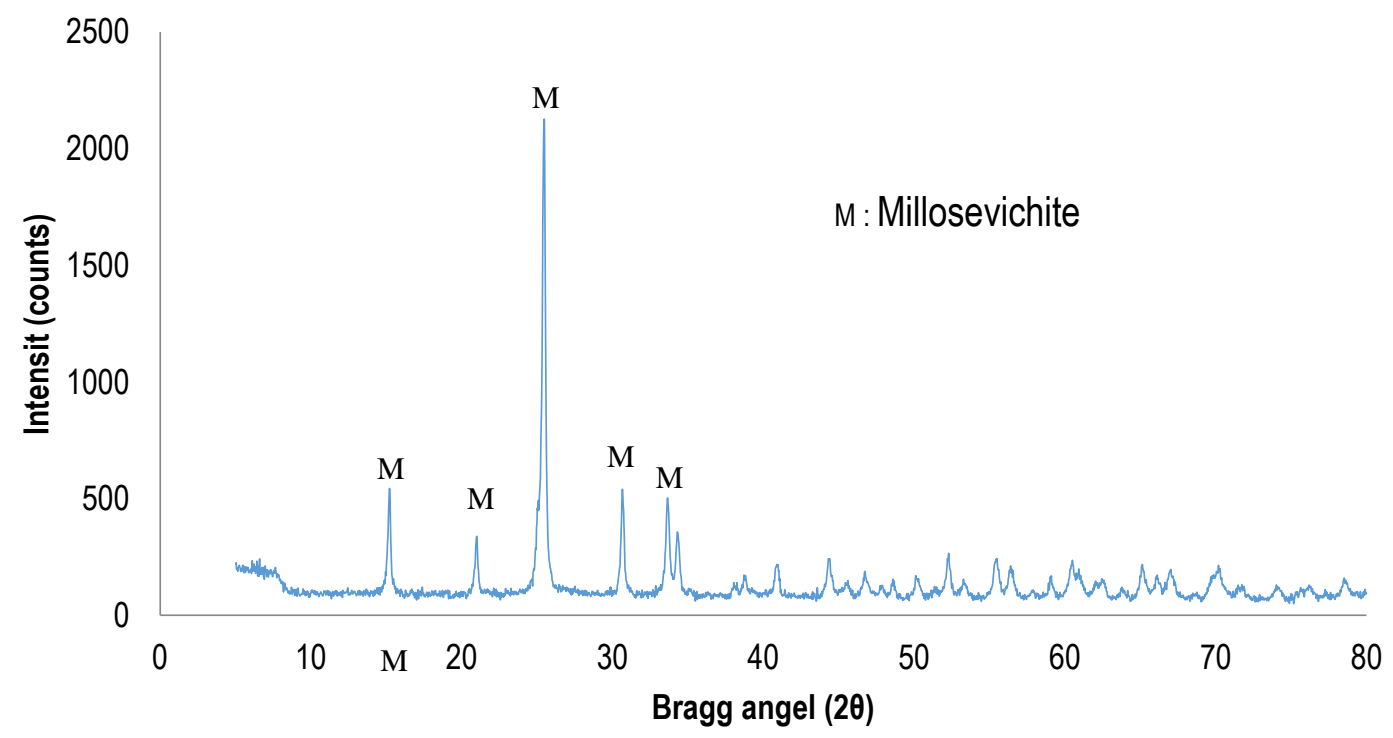

Figure 5: X-ray Diffraction Pattern of Aluminum Sulfate 


\section{Bawa et al: Synthesis of Gamma-Alumina from Kankara Kaolin as Potential Zeolite Active Matrix}

Millosevichite, a crystal phase of aluminium sulfate was obtained when the ammonium alum was calcined at $800^{\circ} \mathrm{C}$ for $3 \mathrm{~h}$ as shown in Figure 5. The indicated peaks of milosevichite are in accordance with comprehensive work done on mineral identification (Chen, 1977). Gammaalumina was obtained at $850^{\circ} \mathrm{C}$ after $3 \mathrm{~h}$ soaking as shown in Figure 6. The XRD pattern for this sample showed broad peaks at d-spacing of $1.43 \AA$ A $1.99 \AA$ and $2.43 \AA$ which largely matched with the commercial and standard XRD pattern of gamma-alumina and conformed with earlier reports (Santos, 2000; Aderemi, 2011).

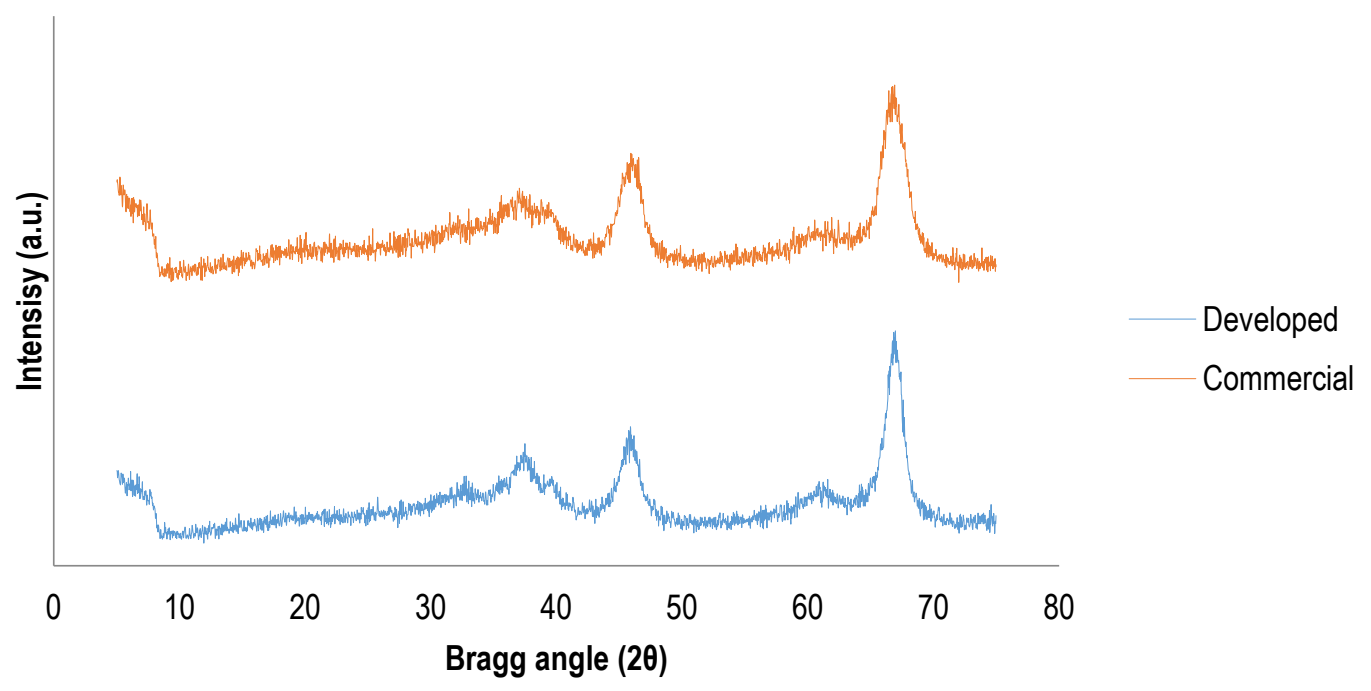

Figure 6: X-ray Diffraction Pattern of Gamma-Alumina

The chemical composition of the gamma-alumina obtained from the XRF analysis (Table 1) showed that the $\mathrm{Al}_{2} \mathrm{O}_{3}$ content was $85.02 \%$ with
$4.76 \% \mathrm{SO}_{3}$ and $5.16 \%$ loss on ignition. This suggested that there were $\mathrm{SO}_{3}$ and water still left in the structure.

Table 1: Chemical composition of products obtained (XRF analysis)

\begin{tabular}{llllll}
\hline Oxides & $\mathrm{Al}_{2} \mathrm{O}_{3}$ & $\mathrm{SiO}_{2}$ & $\mathrm{SO}_{3}$ & $\mathrm{LOl}$ & Other Oxide \\
$800^{\circ} \mathrm{C} / 3 \mathrm{~h}$ & 39.00 & $\mathrm{ND}^{*}$ & 59.51 & $\mathrm{ND}^{* *}$ & 1.51 \\
$850^{\circ} \mathrm{C} / 3 \mathrm{~h}$ & 85.02 & $\mathrm{ND}^{*}$ & 4.76 & 5.16 & 5.05 \\
\hline
\end{tabular}

$\mathrm{ND}^{*} \quad$ Not detected $\quad \mathrm{ND}^{* *} \quad$ Not determined

The morphology of the gamma-alumina is presented in Figure 7. Each lump represents a macrostructure consisting of agglomerated particles with irregular particle shapes. Therefore, it could be deduced from the images that the gamma-alumina possessed a lumpy anhedral morphology (Salahudeen, 2014), this further shows the amorphous nature of the gammaalumina produced as already shown by the XRD result. The structural morphology was a flake-like euhedral morphology, which is in agreement with reported works (Aderemi and Hameed, 2011; Salahudeen et al., 2014). 


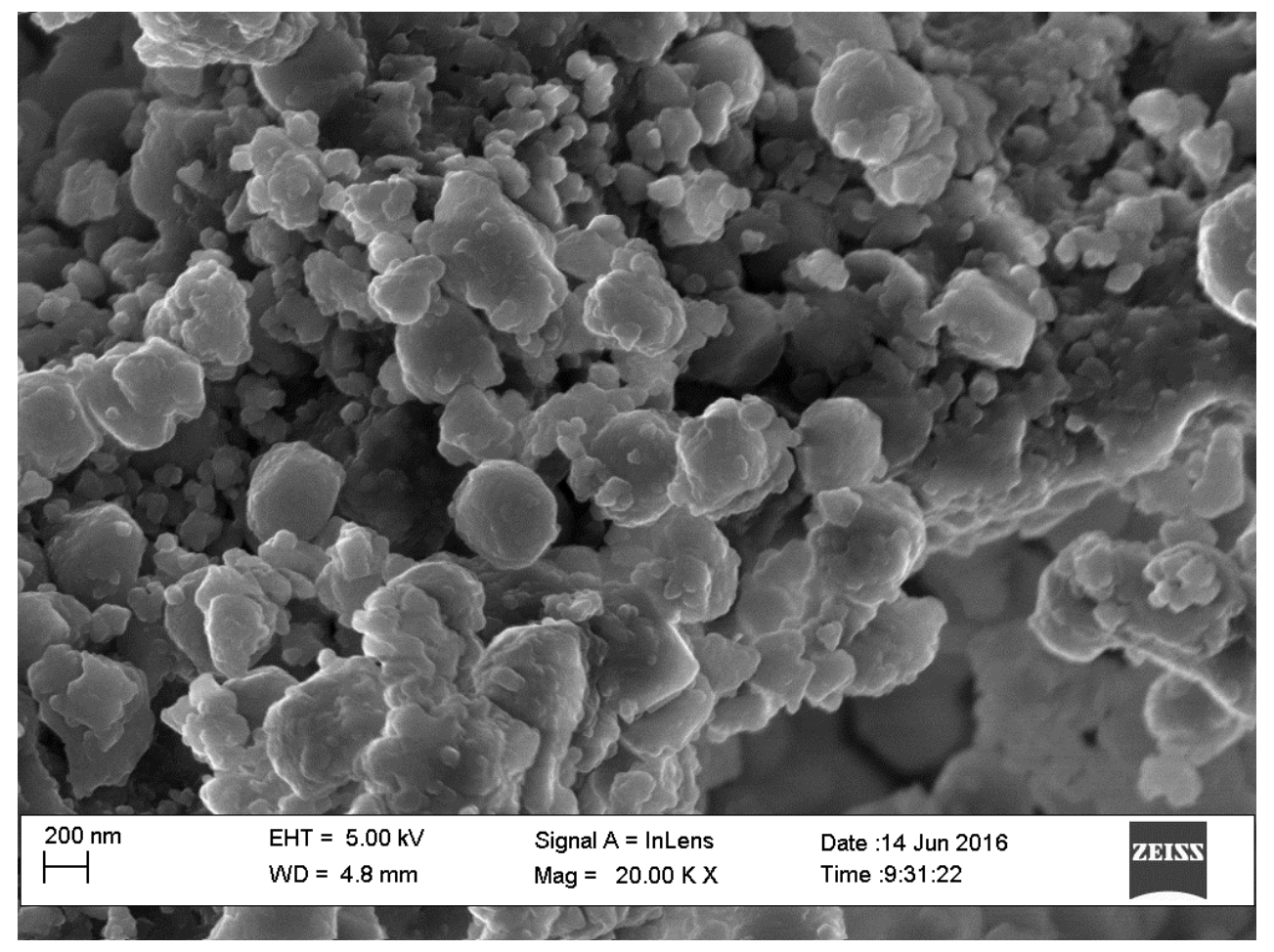

Figure 7: SEM Image of Gamma-Alumina Synthesized from Kankara Kaolin

\section{CONCLUSION}

It may be concluded from the investigations that gamma-alumina with large specific surface area $\left(166 \mathrm{~m}^{2} / \mathrm{g}\right)$ was developed from Nigerian Kaolin, which may find application as catalyst support material. Thermal decomposition of ammonium alum at $800^{\circ} \mathrm{C}$ and below did not yield alumina rather crystalline alumiun sulfate was ontained.

\section{REFERENCES}

Aderemi, B.O. and Ajayi, O.A. (2009). Sourcing Aluminum from Kaolin Clay for Metallurgical Industry. Proceedings of Nigerian Materials Congress, Akure, Nigeria, pp 104-107.

Aderemi, B.O. and Hameed, B.H. (2011). Alumina from kaolin - Extraction and Characterization. Proceedings of the $27^{\text {th }}$ Nigerian Metallurgical Society, Abuja, pp 75-80.

Ahmed, A.S. and Onaji, P.B. (1987). The Effect of Beneficiation on the Propeties of some Nigerian refractory Clays.
This studies shows that Kankara Kaolin is a promising material for the production of gammaalumina.

\section{ACKNOWLEDGEMENT}

The authors are grateful to Petroleum Technology Development Fund, Abuja for their funding.

Journal. of Nigeria Society of Chemical Engineers. 6(2): 119-129.

Čejka, J., Corma, A. and Zones, S. (2010). Zeolite and Catalysis: Synthesis, Reaction and Applications. Wiley-VCH verlag GmbH \& Co., Weinheim. pp. 457.

Chen, P. (1977), "Tables of Key Lines in Xray Powder Diffraction Patterns of Minerals in Clays and Associate Rocks", Indiana, Bloomington, pp. 30-40.

Corma, A. (1992). In Zeolite Microporous Solids: Synthesis, Structure and Reactivity. NATO ASI Series, Edns., Derouane, E. G., Lemos, F., Naccache, C., and Ramoa F: Academic Publishers; 352: pp 373-436. 
Edomwonyi-Otu, L.C. and Aderemi, B.O. (2009). Alums from Kankara Kaolin: Journal of Research in Engineering. 6 (1): 105-111.

Hosseini, S. A., Niaei, A. \& Dariush, S. (2011). Production of $\mathrm{y}-\mathrm{Al}_{2} \mathrm{O}_{3}$ from Kaolin: Open Journal of Physical Chemistry. 1: 23-27.

Htay, M.M and Mya, M.O. (2008). Preparation of Zeolite $Y$ Catalyst for Petroleum Cracking: World Academy of Science, Engineering and Technology. 48: 114-120.

Kloprogge, J.T., Ruan, H.D. and Frost, R.L. (2002). Thermal Decomposition of Bauxite Minerals: Infrared Emission Spectroscopy of Gibbsite, Boehmite and Diaspore. Journal of Materials Science. 37(6): 1121-1129.

Meor-Yusoff, M.S. and Masliana, M. (2007). Synthesis of Alumina Using the Solvothermal Method: The Malaysian J. of Analytical Science. 11 (1): 262-268.

Salahudeen, Nurudeen (2012). Development of Catalyst Support Material from Pindiga Bentonitic Clay. MSc. Thesis Department of Chem. Eng., ABU, Zaria. (Unpublished).

Salahudeen, N., Ahmed, A. S., Al-Muhtaseb, A. H., Dauda, M., Waziri, S. M, and Jibril, B. Y. (2014), Synthesis of Gamma Alumina from Kankara Kaolin Using a Novel Technique. Applied Clay Science, 105-106, 170-177.

Santos, P.S., Santos, S. H. and Toledo, S.P. (2000). Standard Transition Aluminas. Electron Microscopy Studies. Material Resources, 3(4): 97-105.

Scherzer, J. (1993). In Fluid Catalytic Cracking: Science and Technology, Magee, J. S., Mitchell, M. M., Eds.; Elsevier: Amsterdam, pp 23.

Scherzer, J. (1994). In Fluid Catalytic Cracking III: Materials and Processes; Occelli, M. L., and O'Connor, p., Eds.; American Chemical Society: Washington, DC, pp 46-50.
Wang, L. J., Wen, M. F., Li, Y. S., Yang, D., Chen, J. and Song, C. L. (2006). Preparation of High Surface Area, Large Pore Volume Alumina by Using $\beta$ Cyclodextrin as a Non-Surfactant Template: Chinese Chemical Letters. 17 (9):1239-1242.

Wefers, K. and Misra, C. (1987). Oxides and Hydroxides of Alumina. Alcoa Technical paper 19, Reveised, Aluminum Company of America, Pennsylvania, pp 54-58. 